\title{
The Ad Hoc Discussion Group on Serials Data Bases: Its History, Current Position, and Future
}

\author{
Richard ANABLE: Coordinator, York University Libraries, Toronto, \\ Ontario, Canada.
}

\section{HISTORY}

The Ad Hoc Discussion Group on Serials Data Bases was formed as a result of an informal meeting held during the American Library Association's Conference in Las Vegas on June 26, 1973. Those in attendance were primarily interested in the generation and maintenance of machine-readable union files of serials. (This author's involvement in that meeting and the later activities of the group stems from a contract between the National Library of Canada and York University concerning an investigation of the problems associated with machine-readable serials files.)

It was intended to be a relatively small and informal meeting of about ten individuals. The meeting was by no means closed, but it was not widely advertised. However, twenty-five individuals representing twenty institutions on the national (both the United States and Canada), regional, and local levels attended.

At the meeting there was a great deal of concern expressed about:

1. The lack of communication among the generators of machine-readable serials files.

2. The incompatibility of format and/or bibliographic data among existing files.

3. The apparent confusion about the existing and proposed bibliographic description and format "standards."

There was general agreement that something should and could be done about these problems, and that the formation of a group specifically concerned with the generation and maintenance of machine-readable serials data bases would at least improve the communications aspect of the overall problem. (Poor communication was thought by some to be at the root of the other problems.) It was also suggested that such a group could lay the groundwork for solving some of the compatibility problems, by presenting proposals on various aspects of the overall problem. These proposals might be used as guidelines for any new projects or revisions of existing ones. It 
was felt very strongly that the time factor was crucial if the efforts of such a group were to be useful, particularly to several of the institutions represented at the meeting.

There was also a concern that the activities of the group should not parallel or duplicate any work already being undertaken by other groups. While various ALA committees were dealing with some aspects of the overall problem, no one committee seemed to be addressing its entire scope. The Association of Research Libraries was conducting a study of the existing serials data bases held by their member institutions, but was not currently addressing the overall problem, particularly with regard to the union list activities. It was suggested that direct communication with that committee be established.

The net result of this first meeting was that the Discussion Group was formed and several meetings were scheduled. Cynthia Pugsley from the University of Waterloo libraries, Jay Cunningham from the University-wide Library Automation Program, University of California, and this writer were requested to prepare a position paper outlining the need for such a group.

In July, the minutes of the June 26 meeting and the position paper were distributed. In the meantime a Steering Committee was arbitrarily selected. The Council on Library Resources agreed to fund a meeting of that committee to be held September 21 at York University in Toronto. The Steering Committee was made up of representatives from the Council on $\mathrm{Li}$ brary Resources (CLR), Northwestern University, the Canadian Union Catalogue Taskgroup and its Subgroup on the Serials Union List, the State University of New York (SUNY), the University of California University-wide Library Automation Program (ULAP), the Association of Research Libraries (ARL), the Joint Committee on the Union List of Serials (JCULS), Ohio College Library Center (OCLC), the National Serials Data Program (NSDP), the Library of Congress (LC), the National Library of Canada (NLC), Université Laval, International Serials Data System (ISDS)/Canada, and an observer from the British Library.

The purpose of the meeting was:

1. To establish a mechanism for creating a set of "agreed-upon practices for converting and communicating machine-readable serials data."

2. To establish a mechanism for cooperatively converting a comprehensive retrospective bibliographic data base of serials.

To further these ends, the following subcommittees were established:

1. Holding Statement Notation

2. Working Communications Conventions

3. Authority Files

4. Cooperative Conversion Mechanism

The Steering Committee recognized the need for swift action on the development of "agreed-upon practices." Consequently, this job was delegat- 
ed to the Holding Statement Notation and the Working Communications Conventions subcommittees. It deferred action on the question of a cooperative conversion effort until a report was received from that subcommittee at the next Steering Committee meeting scheduled for October 22, 1973 during the American Society for Information Science meeting in Los Angeles.

On October 10, three of the four subcommittees met for very brief sessions at the Library of Congress. The most significant results came from the Cooperative Conversion Subcommittee which recommended that: (1) a proposal for a cooperative project be prepared as soon as possible; and (2) that the conversion vehicle for such a project be the OCLC facilities.

At the next Steering Committee meeting these recommendations were accepted and the coordinator was asked to prepare a draft of a proposal for review by the Cooperative Conversion Subcommittee. At this time the proposal is being prepared.

The question of the need for formal affiliation with one or more of the existing professional organizations had repeatedly been raised at the various meetings. It was initially decided to inform the appropriate organizations of our existence and intentions, and to cooperate whenever and wherever our activities overlapped. When the group decided to prepare a proposal for a cooperative conversion project, the need for such affiliation increased dramatically.

At the October 22 meeting, the Association of Research Libraries indicated a positive interest in our exploring that possibility further with them. They asked for a more detailed definition of our goals and plans, which is also being prepared.

Generally the reaction of the group toward some kind of organizational arrangement with ARL, if assurance could be made regarding the participation of non-ARL institutions, was favorable.

Another question that lingers is whether it would be advisable to have a formal dual affiliation with both ARL and a second professional organization. At this point the question is still open.

\section{CURRENT POSITION}

Thus far the activities of the group have addressed the problems of:

1. The improvement of communications among institutions engaged in the generation or maintenance of serials data bases.

2. The establishment of a set of "agreed-upon practices."

3. The investigation of future means of cooperative or coordinated serials record conversion of retrospective titles.

The reasons for these efforts are obvious. We are currently all spending much time and money on noncooperative and uncoordinated local and regional conversion, and few of us are satisfied with the results.

Through improved communications among conversion efforts, we hope 
to establish a set of "agreed-upon practices" which should increase the interfiling compatibility. This in turn should reduce the cost to each institution. The use of a common centralized data collection vehicle will minimize redundant conversion.

The problems associated with the generation and maintenance of union files of serials have multiplied in the last decade with the introduction of the Anglo-American Cataloguing Rules (AACR), establishment of the International Serials Data System (ISDS), the presentation of the International Standard Bibliographic Description for Serials (ISBDS) proposal, the distribution of the Library of Congress MARC Serials records, and the increasing role played by the indexing and abstracting services as points of access to serials lists of all types.

Individually our institutions cannot comprehensively attack all of these aspects. If attacked independently, there is little chance of similarity of approach; if attacked jointly, through the establishment of a set of "agreed-upon practices," similarity will be greater. If attacked jointly through a cooperative conversion effort, the resulting file will be equally usable to all the participants.

It is the primary objective of the Cooperative Conversion Project to establish a relatively comprehensive bibliographic data base of serials titles within a time frame which would eliminate the necessity for redundant and costly conversion efforts on the local and regional levels. The prime use of the resulting data base is intended to be the support of union list of serials activities.

The secondary objectives are:

1. To assist the national libraries of both countries (Canada and the United States) in the establishment of a computer-maintained (and hopefully remotely accessible) serials data system. This will be accomplished partly by the very existence of the resulting data base, and partly by the experience gained in its establishment.

2. To assist in the definition of the roles of the regional or resource centers in such enterprises.

3. To provide a source data base for use within the International Serials Data System, and to seek the active participation of the Canadian and United States National Centers.

The intention of the Cooperative Conversion Project is to establish a comprehensive data base of serials titles in such a way as to accommodate the past, present, and future standards for format, description, and identification, when they can be identified. It is not the intention of this group to establish any new standards in any area.

The proposed record structure will be a composite record complying with the ISO/2709 format standard on level one (structure), and will attempt to reconcile the minor conflicts among the International Serials Data System's Guidelines, the National Serials Data Program internal format, the Library of Congress' MARC-S format, and the draft of the Ca- 
nadian MARC Serials format on levels two and three (content designators and content). The problems here appear to be technical in nature and by no means insurmountable. Thus far the communication among the participants (including representatives from three of the four areas) has been most encouraging.

The record will be based on a minimum set of data elements established to provide enough data to support the union list functions. However, this is a minimum and not a maximum set. It is basically a convention below which a record will be considered incomplete and above which it will be considered acceptable. There probably will be two additional categories of data elements besides those that are required: (1) required if readily available; and (2) not required by the system, but acceptable. "Required if readily available" covers those situations where complete bibliographic data are available at the time of conversion, such as where Library of Congress data are present. If the data are there, it is cheaper to convert at that point than at a later date. For this category and the "not required but acceptable" category, a set of agreed-upon practices will be in effect to ensure that if a data element is converted it will be consistent in content with similarly tagged fields.

Since at the time of this writing the proposed working communication conventions have not been finalized, it is not possible for the reader to judge whether the minimum set of data elements will meet his local or regional requirements. At this stage it appears that the set will probably include over thirty elements and will have as a subset the ISDS data element requirements.

The conversion project is intended not to compete with any existing or planned programs at either the Library of Congress or the National Library of Canada. In fact, it is intended to complement activities in which these two institutions might be engaged. The distribution of the LC MARC-S records, and the similar proposed service by the National Library of Canada, deal primarily with new titles or title changes, and not with the conversion of retrospective titles. While it is the stated intent of the NSDP to attack this area (retrospective titles), thus far it has not been funded to do so. In fact the active involvement of both national libraries and their ISDS centers is anticipated since their contribution would be inappropriate to duplicate.

It is intended that the resulting data base be made available to the ISDS International Center and thus the rest of the international library community.

While the direct participation in the conversion effort may well be limited to a manageable number of institutions, this should not deter any institution from direct involvement in the deliberations of the group. What is requested is that the prospective participants have a serious interest in the solving of problems within the short time frame allowed. 


\section{FUTURE}

To repeat, the basic goals of the group are:

1. To improve the communication among the generators of serials data bases.

2. To establish a set of "agreed-upon practices."

3. To establish a mechanism for the cooperative conversion of a comprehensive serials data base.

The first goal will be an on-going effort, probably carried through by one or more existing organizations. The second goal, we hope to have partially completed by the time ALA meets in Chicago in January 1974, through the presentation to the Steering Committee of the reports of the various subcommittees. The third goal will be accomplished in stages. By ALA Midwinter we hope to have a concrete proposal that can be presented to all prospective participants, to funding agencies, and to the library community as a whole. Since time is one of the items to be optimized, we feel that we should have the project launched no later than the end of the second quarter of 1974.

The basic approach being proposed in this document can be characterized in the following ways:

1. A limited number of large institutions (5-15), or centers representing large institutions, will use a single on-line data collection facility, such as the Ohio College Library Center (OCLC), to convert their retrospective serials files.

2. One or more large bibliographic files will be used as a base file (possibly the Minnesota Union List of Serials file) to which new records or fields can be added.

3. The conversion requirement will be based on:

(a) the building of a composite record incorporating the AACR, ISDS, and proposed ISBD (S) requirements.

(b) minimum set of data elements basically for union list of serials purposes.

(c) the concept of an expandable record able to incorporate:

(1) variant entry approaches, and

(2) available (but not required) data elements.

Such an approach is a series of compromises, the first of which deals with the trade-off between time and cost.

One argument which has been offered against the concept of collecting an "incomplete" serials record is that the total cost to the library community in the long run will be greater than if a complete record conversion were to be done initially. This argument is a carryover from the similar discussion concerning monographs.

However, we must recognize the following:

1. Serials records are of a dynamic nature; what is true for a title this 
year probably will not be true next year. The more comprehensive the data element set, the more true this becomes.

2. The cost curve dramatically increases as the number and type of data elements increase.

3. The increased time required to collect, edit, and control an exhaustive data element set will seriously protract the time frame of such an effort.

4. The time frame is one of the prime targets for optimization. Any massive additional data collection requirement will compromise that goal.

There are no conclusive studies in the area of serials conversions which suggest that the "total" record conversion approach would be less expensive in the long run than a base record conversion approach. We do not know what the total conversion effort is now, but it is guessed to be significant.

The utilization of most of the existing files is primarily for catalogs or for location services which the proposed minimum data set will accommodate. Only a limited number of institutions have experimented with serials check-in or other functions requiring more complete records.

The building of a composite record incorporating the various bibliographic standards is easily justified. Such a record must be accessible via past, current, future, and popular practices.

The ability to incorporate alternative applications of the same standards is also important, particularly in those cases where the rule is open to interpretation. This is very important if there is no centralized authority to control the application of a specific standard.

The ability to convert additional data elements which are readily available but not required, is also an important capability since it will reproduce a more complete record at a reasonable cost. Keeping the number of contributing institutions to a relatively small number simplifies the control aspects of the project.

Using a central on-line (remotely accessible) system such as OCLC reduces the amount of software development required and reduces the degree of redundant conversions. It also will enable us to start conversion in a time frame otherwise impossible.

The use of at least one large bibliographic file such as MULS decreases the amount of original conversion, thus shortening the total time frame. The use of multiple starting data bases increases the matching requirements of similar records among the data bases but further reduces the original effort. The problem of selecting data bases is being studied.

\section{SUMMARY}

I have attempted to define in this article the history, the current position, and the future plans of the Ad Hoc Discussion Group on Serials Data Bases. We have tried to include in the deliberations of the group as many of the interested parties as possible. Omissions do exist, not by intent, but 
because of a lack of complete information and poor communication. I have tried to act with speed because of the need expressed by the participants. The group is not a closed shop. Any institution seriously desiring to make contributions is welcome. Please consider this an open invitation. Any documentation desired is readily available from me, as the coordinator.

The willingness of the participants to cooperate and to make compromises has thus far exceeded all expectations, particularly in those areas where problems were expected. It has truly been a group effort. I would like to especially thank the National Library of Canada, the Library of Congress, and the National Serials Data Program for the cooperation they have given to the regional organizations which have been the backbone of this effort. 